\title{
ИМПЛИКАЦИЯ СУБЪЕКТА В ПРЕДЛОЖЕНИЯХ С ПАССИВНЫМ ЗАЛОГОМ (НА МАТЕРИАЛЕ НЕМЕЦКОГО И РУССКОГО ЯЗЫКОВ) ${ }^{1}$
}

\section{IMPLICATION OF THE SUBJECT \\ IN SENTENCES WITH A PASSIVE VOICE \\ (BASED ON THE MATERIAL OF GERMAN AND RUSSIAN)}

\section{A. Chervony \\ E. Murashova}

Summary: The article examines the implementation of subject-object relations in passive constructions of the Russian and German languages based on the material of the original and translated texts of M. Bulgakov's novel «The Master and Margarita». The study of the original and translated texts showed a significant predominance of the use of passive syntactic constructions in the German language.

German passive constructions correspond to different types of Russian sentences (constructions of uncertain-personal and generalized-personal sentences with an active voice, sentences with a reflexive verb and with a "passive participle», etc.)

The producer of the action in passive constructions not only does not take the position of the subject, but can be formally implicit in both languages, although mentally, in consciousness it is always present.

The real doer is implicit in passive constructions, so the object of the performed action is in the focus of the statement.

Keywords: passive construction, subject, object, passive voice, comparative analysis.
K ак известно, действительный и страдательный залоги в структуре различных языковых систем представляют подлежащее с разных позиций, в действительном залоге подлежащее преимущественно - субъект (производитель действия), в пассивном залоге - это объект, на который действие направлено. Когнитивная диспозиция «активный субъект - пассивный объект» актуализируется носителями конкретных языков с учётом осмысления ситуации и возможностей используемой субъектом речи языковой системы для описания того или иного фрагмента действительности.

В данной статье сосредоточим наше внимание на ак-

\author{
Червоный Александр Михайлович \\ Д.филол.н., дочент, Таганрогский институт \\ имени А.П. Чехова (филиал) ФГБОУ ВПО «РГЭУ (РИНХ)» \\ ckutrik@yandex.ru \\ Мурашова Евгения Анатольевна \\ К.филол.н., доцент, Таганрогский институт \\ имени А.П. Чехова (филиал) ФГБОУ ВПО «РГЭУ (РИНХ)» \\ shenetschka@rambler.ru
}

Аннотация: В статье на материале оригинального и переводного текстов романа М. Булгакова «Мастер и Маргарита» рассматривается реализация субъект-объектных отношений в пассивных конструкциях русского и немецкого языков. Исследование оригинальных и переводных текстов продемонстрировало значительное преобладание использования в немецком языке пассивных синтаксических конструкций. Немецким пассивным конструкциям соответствуют разные типы русских предложений (неопределённо-личные, обобщённо-личные ( активным залогом, предложения с возвратным глаголом, со «страдательным причастием» и др.)

Субъект - производитель действия в пассивных конструкциях не только не занимает позицию подлежащего, но может в обоих языках быть формально имплицитен, хотя ментально, в сознании он присутствует всегда.

Ввиду имплицитности реального деятеля в пассивных конструкциях в фокусе высказывания оказывается объект осуществляемого действия.

Ключевые слова: пассивная конструкция, субъект, объект, страдательный залог, сопоставительный анализ. туализации пассивного вектора данной диспозиции на материале русского и немецкого языков, сопоставляя оригинальный и переводной текст романа М. Булгакова «Мастер и Маргарита».

Исследование реализации действительного и страдательного залога в системе русского и немецкого языков в качестве логико-семантического представления субъектно-объектных отношений, проводится нами с привлечением алгоритмов комплексного сопоставительного исследования, базирующегося на доминантных положениях антропоцентрической и системноструктурной парадигм, приёмах контекстуального и

Исследование выполнено при финансовой поддержке Российского фонда фундаментальных исследований (РФФИ) в рамках научного проекта № 19-012-00062 «Полифония семантического субъекта (на материале русского, французского, английского и немецкого языков», проводимого в ФГБОУ ВО «РГЭУ (РИНХ)»; руководитель - доктор филол. наук, доцент, заведующий кафедрой немецкого и французского языков А.М. Червоный 
сопоставительного анализа.

Использование в практике речи действительного и страдательного залогов осуществляется с помощью морфосинтаксических средств, которые детерминированы условиями коммуникативной ситуации и конвенционально закреплёнными грамматическими нормами немецкого и русского языков. Исследование частотности реализации действительного и страдательного залога позволяет представить их номенклатуру и уточнить функционал пассивных залоговых форм.

Общее для разных языковых систем противопоставление значения активности / пассивности реализуется в соответствии с доминированием одного из наличествующих в высказывании актантов (субъекта действия или объекта, испытывающего воздействие). Реализация пассивного вектора в высказывании имеет место в процессе референции говорящим фрагмента действительности, в которой объект подвергается (воз)действию. При этом эксплицируемое (воз)действие оказывается в большей степени связанным с объектом, чем с субъектом, который данное действие реализует. Доминирование в предложении объектного актанта является определяющим параметром в ходе идентификации семантики пассивности.

Парадигмы действительного и страдательного залогов различных языков, в том числе немецкого и русского, противопоставленные с учётом обозначенного выше универсального параметра идентификации пассивности, отличаются разным контентом, разным объёмом и частотностью актуализации.

Традиционно считается, что частотность актуализации страдательного залога в немецком языке в текстах различных жанров значительно выше, чем в русском языке [2, с. 169-170; 4, с. 284-286]. Кроме того, пассивный залог представлен в немецком языке двумя вариантами. Первый (пассив процесс) образуется с помощью вспомогательного глагола werden в coответствующей условиям контекста временной форме и причастия II смыслового глагола. Данная форма пассивного залога описывает процесс или действие. Второй (пассив результат или пассив состояния) - образован с помощью вспомогательного глагола sein в соответствующей временной форме и причастия II смыслового глагола. Здесь речь идёт об описании результата действия [7, с. 550; 4, с. 2].

Пассив процесс (Vorgangspassiv).

Das Haus wird gebaut (Präsens Passiv Vorgang). Das Haus wurde gebaut (Präteritum Passiv Vorgang). Das Haus ist gebaut worden (Perfekt Passiv Vorgang). Das Haus war gebaut worden (Plusquamperfekt Passiv Vorgang).
Das Haus wird gebaut werden (Futurum I Passiv Vorgang).

Das Haus wird gebaut worden sein (Futurum II Passiv Vorgang).

Пассив результат (Zustandspassiv). Das Haus ist gebaut (Präsens Zustandspassiv). Das Haus war gebaut (Präteritum Zustandspassiv). DasHausistgebautgewesen(PerfektZustandspassiv). Das Haus war gebaut gewesen (Plusquamperfekt Zustandspassiv).

Das Haus wird gebaut sein (Futurum I Zustandspassiv). Das Haus wird gebaut gewesen sein (Futurum II Passiv Vorgang).

Кроме того, как пассив процесс, так и пассив результат в немецком языке могут употребляться в конструкциях с модальными глаголами.

\section{Das Haus kann gebaut werden.}

Das Haus kann gebaut sein.

Пассивные конструкции используются в немецком языке значительно чаще, чем в русском, в то время как русский язык обладает более широкой палитрой синтаксических средств выражения субъектно-объектных отношений, позволяющих акцентировано обозначить объект воздействия либо представленный в разной степени определенности субъект - реального деятеля.

Этим объясняется наличие многочисленных трансформаций при переводе идентичных контекстов с русского языка на немецкий и наоборот. Как показывает анализ фактического материала, неопределённо-личные и обобщённо-личные предложения с активным залогом могут заменяться при переводе на немецкий язык пассивными конструкциями. При этом может происходить трансформация косвенного дополнения предложения активного залога в подлежащее предложения пассивного залога.

Например:

1. Разве я похож на юного бродячего юродивого, которого сегодня казнят? [1, с. 30] - Gleiche ich etwa dem gottesnärrischen jungen Landstreicher, der heute hingerichtet wird? [6, c. 45].

2. Имя того, кого сейчас при вас отпустят на свободу... [1, с. 34] - Der Name dessen, der jetzt vor aller Augen freigelassen wird, ist... [6, c. 51].

3. Иуду этой ночью уже зарезали [1, с. 306] - Judas ist in dieser Nacht erstochen worden [6, c. 435].

Партиципант, испытывающий на себе воздействие со стороны субъекта, может быть выражен косвенным дополнением:

«Раз, два... Меркурий во втором доме... луна ушла... шесть - несчастье... вечер - семь...» - и громко и радост- 
но объявил: - Вам отрежут голову! [1, с. 12] - Laut und freudig erklärte er: Ihnen wird der Kopf vom Rumpf getrennt! [6, c. 18].

Возвратные глаголы русского языка при переводе на немецкий язык также могут стать эквивалентами пассивных конструкций.

\section{Например:}

1. И эта казнь сейчас совершится на Лысой Горе! [1, c. 33] - Die Hinrichtung wird ohne Aufschub auf dem Schädelberg vollzogen! [6, c. 50].

2. Партия отменяется [1, с. 335] - Die Partie wird unterbrochen [6, c. 236].

Сочетания страдательных причастий с глаголом быть заменяются пассивом (наиболее часто при обозначении действий, свершившихся в прошлом).

\section{Например:}

1. Намеченное Маргаритой очко было пробито [1, c. 259] - Das von Margarita gezeichnete Auge war getroffen [6, c. 368].

Сопоставительный анализ различных способов выражения субъект-объектных отношений в русском и немецком языках показал: пассивным конструкциям немецкого языка (они взяты за 100\%), соответствуют 31\% неопределённо-личных и обобщённо-личных предложений с активным залогом в русском языке, 26\% русских предложений с неодушевлённым подлежащим в третьем лице, 24\% предложений с возвратными глаголами, 19\% представляют синтаксические конструкции со «страдательным причастием в прошедшем времени + глагол «быть».

Пассив состояния в переводах использован значительно реже (7\% из 100\%), преимущественно как эквивалент страдательных причастий прошедшего времени.

\section{Например:}

- Ну-с, Маргарита Николаевна, все сделано [1, с. 272] - Nun, Margarita Nikolajewna, alles ist getan $[6$, c. 386].

Пассивная форма немецкого языка коррелирует с отглагольными существительными русского языка.

Например:

И интереснее всего в этом вранье то, - сказал Воланд, - что оно - вранье от первого до последнего слова [1, с. 257] - Das interessanteste an diesem Schwindel, -sagte Voland, - alles vom ersten bis zum letzten Wort ist gelogen [6, c. 365].

Таким образом, исследованный нами материал ори- гинальных и переводных текстов подтвердил значительное преобладание использования в немецком языке пассивных синтаксических конструкций, а также продемонстрировал факультативность выражения субъекта действия, что способствует его транспозиции в зону контекста. Универсальность данного явления подтверждается наличием в разных языковых системах средств построения так называемых «безагентных» конструкций [3, с. $401 ; 8$, с. 266; 9, с. 57; 10, с. 2-6] и тенденцией к выражению обобщающего значения.

Довольно частое употребление лексических единиц широкой семантики, выражающих семантический субъект, в обобщающих высказываниях в немецкоязычных конструкциях с пассивным залогом свидетельствует о его деконкретизации, и таким образом о эксплицитном устранении субъекта [5, с. 186-187].

Следует отметить, что обобщающее значения может проявляться как в отношении отображаемой ситуации в целом (1), так и в отношении кого-либо отдельно осуществляемого действия (2):

1. Es wurde eine langweilige Ausfragerei geworden [6, c. 112].

2. Es wurde beschlossen, in der Mittagspause zu singen, da alle sonstige Zeit bereits von Ler-montow und dem Damespiel ausgefüllt war [6, c. 272].

Само действие в отношении неконкретизированного субъекта может быть связано с

1) физическим воздействием:

- Er wurde in der Nähe der Stadt getötet [6, c. 452];

2) вербальным воздействием:

- Was ihm auch zugesagt wurde [6, с. 478];

3) перцептивным воздействием на воспринимаемый объект:

- „Psychologisch gesehen, ist er ein typischer kleiner Kulak", sagte Iwan,... [6, c. 94];

4) фактивным воздействием:

- Als er dort ankam, wohin ihn der Finanzdirektor geschickt habe, sei er sofort vorgelassen und sehr aufmerksam angehört worden [6, c. 216];

5) когнитивным воздействием, направленное на познание объекта:

In der hiesigen Staatsbibliothek sind echte Handschriften des Schwarzkünstlers Gerbert d'Aurillac aus dem zehnten Jahrhundert entdeckt worden [6, c. 23].

Как видим, обобщающее значение пассивной конструкции в немецком языке в подавляющем большинстве случаев позволяет представить действие без формального уточнения его инициатора.

Представляя один и тот же фрагмент действительности, носители русской и немецкой языковых систем объективируют различные концептуальные структуры 
посредством доступных им форм экспликации субъекта как производителя действия, так и объекта, на которое действие направлено. Это объясняет дифференциацию использования действительного и страдательного залогов, а также широкую палитру трансформаций при переводе идентичных контекстов художественного дискурса, в нашем случае оригинального и переводного текстов романа М. Булгакова «Мастер и Маргарита».

Таким образом, сохранение логико-смысловых отношений при переводе идентичных контекстов с русского языка на немецкий и наоборот требует осуществления лексико-семантических трансформаций ввиду несовпадения содержания, объёма и частоты актуализации парадигм действительного и страдательного залогов данных языков. Русский язык демонстрирует большее синтаксическое разнообразие при выражении идентичной ситуации: немецким пассивным конструкциям соответствуют разные типы русских предложений (неопределённо-личные, обобщённо-личные в активном залоге, предложения с возвратным глаголом, со «страдательным причастием и др.)

Субъект - производитель действия в пассивных конструкциях не только не занимает позицию подлежащего, но может быть в обоих языках формально имплицитен, хотя ментально, в сознании он присутствует всегда.

Ввиду имплицитности реального деятеля в пассивных конструкциях в фокусе высказывания оказывается объект осуществляемого действия.

\section{ЛИТЕРАТУРА}

1. Булгаков М.А. Мастер и Маргарита: Роман. - М.: Современник, 1984. - 367 с.

2. Крушельницкая К.Г. Очерки по сопоставительной грамматике немецкого и русского языков. - М.: ЛКИ, 2008. - 272 с.

3. Лайонз, Д. Введение в теоретическую лингвистику = Introduction to theoretical linguistics / Дж. Лайонз; пер. с англ. под ред. и с предисл. В.А. Звегинцева. - M.: URSS, 2010. -541 c.

4. Павлова А.В. Несовпадение в употреблении страдательного залога (Passiv) в немецком и русском языках // Высшее гуманитарное образование XXI века: проблемы и перспективы. Материалы IV международной научно-практической конференции. В 2-х томах. - Самара: СГСПУ, 2009. - С. 283-286.

5. Червоный А.М., Мурашова Е.А. Лексические и морфосинтаксические средства выражения семантического субъекта в обобщающих высказываниях немецкого и русского языков // Современная наука: актуальные проблемы теории и практики. Серия: Гуманитарные науки. №9, 2020. - С. 185-188.

6. Bulgakov M.A. Gesammelte Werke; Teil: Bd. 3., Der Meister und Margarita : Roman [aus dem Russ. von Thomas Reschke]. - Berlin: Verl. Volk und Welt. - 513 S.

7. Duden. Die Grammatik. - Berlin : Dudenverlag, 2016. - 13415.

8. Primus B. Das unpersönliche Passiv - Ein Fall für die Konstruktionsgrammatik? // Engelberg, Stefan/Holler, Anke/Proost, Kristel (Hrsg.): Sprachliches Wissen zwischen Lexikon und Grammatik. - Berlin, Boston: de Gruyter, 2011. - S. 265-313.

9. Schneider W. Deutsch fürs Leben. Was die Schule zu lehren vergaß. - ÜReinbek bei Hamburg : Rowohlt-Taschenbuch-Verl. 2002. - 222 S.

10. Werner A. Überlegungen zum Passiv im Deutschen und anderen Sprachen, «Argumenthypothese» und «Aspekthypothese» // Zentrum für Allgemeine Sprachwissenschaft, Sprachtypologie und Universalienforschung, - Berlin 2000, S. 1-35.

( ) Червоный Александр Михайлович (ckutrik@yandex.ru), Мурашова Евгения Анатольевна (shenetschka@rambler.ru)

Журнал «Современная наука: актуальные проблемы теории и практики» 